\title{
Isolated Radial Nerve Injury Following Anterior Shoulder Dislocation: Case Report and Literature Review
}

\author{
Hesham Al-Khateeb ${ }^{1 *}$, Maryam Naser ${ }^{2}$, Nicholyn Selvanayagam², Abdul Rahman², and Sadaf Basheer ${ }^{1}$ \\ ${ }^{1}$ Department of Trauma and Orthopaedics, King Hamad University Hospital, Bahrain \\ ${ }^{2}$ Royal College of Surgeons in Ireland, Medical University of Bahrain, Bahrain
}

Submission: May 04, 2017; Published: May 25, 2017

*Corresponding author: Hesham Al-Khateeb, Department of Trauma and Orthopaedics, King Hamad University Hospital, Al Sayh, Bahrain, Tel: +973 3966 9196; Email: drheshamalkhateeb@msn.com

\begin{abstract}
We describe a 74-year-old female patient who presented with an anterior dislocation of the right shoulder due to a fall on an outstretched hand. On examination, there was a profound wrist drop with loss of sensation over the superficial radial nerve distribution, indicating complete radial nerve palsy. A closed reduction of the shoulder was performed. Electromyography at 6 weeks demonstrated severe motor neuropathy in the motor distribution of the radial nerve. Physiotherapy was commenced at 6 weeks and at latest follow-up there was no evidence of recovery of the motor branch of the radial nerve clinically, however, the superficial radial nerve sensation had returned to normal. There was no change in outcome after 1-year follow-up. Although rare, shoulder dislocations associated with isolated radial nerve palsy should be considered and identified at presentation. Nerve injuries with shoulder dislocations require clear documentation pre- and postreduction as this may have significant implications on management and reduction in morbidity.
\end{abstract}

Keywords: Shoulder dislocation; Radial neuropathy; Peripheral nerve injuries

\section{Introduction}

The shoulder is one of the most frequently dislocated joints and is correlated with neurological compromise. Anterior shoulder dislocation is associated with nerve injuries with an incidence ranging from 3 to $21 \%$ based on clinical diagnosis [1]. The incidence of isolated radial nerve injury in primary shoulder dislocation is uncertain. In accordance to one series, the incidence of radial nerve injuries with anterior shoulder dislocation was 7\% [2], whereas in another series the incidence was reported as 18\% [3].

Following an anterior shoulder dislocation, it is important to examine the neurovascular structures as damage to nerves following anterior shoulder dislocation is not uncommon. No damage to nerves other than the suprascapular nerve is described in literature following a low energy trauma [2]. The main aim of this case report is to acknowledge and emphasize the importance of the possibility of isolated radial nerve palsy, and its consideration in the differentials of shoulder instability and dislocation.

\section{Case Report}

We describe a 74-year-old female patient who presented to our institution with an anterior dislocation of the right shoulder following a low energy trauma (fall from a chair) (Figures 1A, 1B $\& 1 \mathrm{C})$. The dislocation was associated with severe pain and loss of range of movement in the right shoulder. On examination, bruising of the right shoulder with loss of normal contour was noted. Initial neurological assessment revealed a profound wrist drop with loss of sensation over the superficial radial nerve distribution, indicating complete radial nerve palsy.

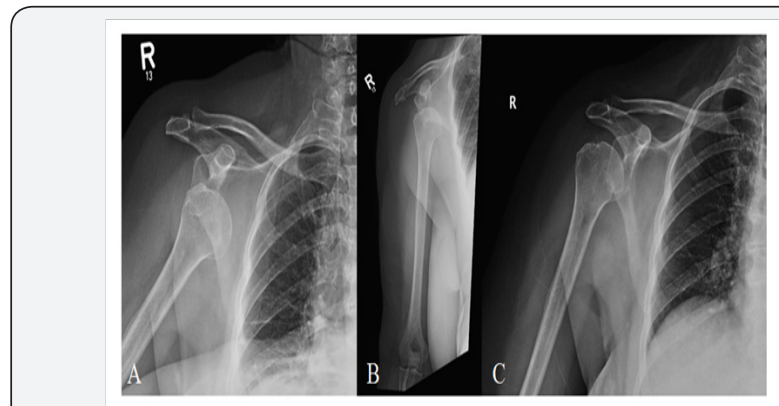

Figure 1: Plain film radiograph AP field pre-reduction.

A. plain film radiograph transcapular pre-reduction,

B. Illustrating anterior dislocation of the humerus with loss of alignment between humeral head and the glenoid; plain film radiograph AP field post-reduction,

C. Illustrating restoration of normal alignment between the humeral head and glenoid. 


\section{Orthopedics and Rheumatology Open Access Journal}

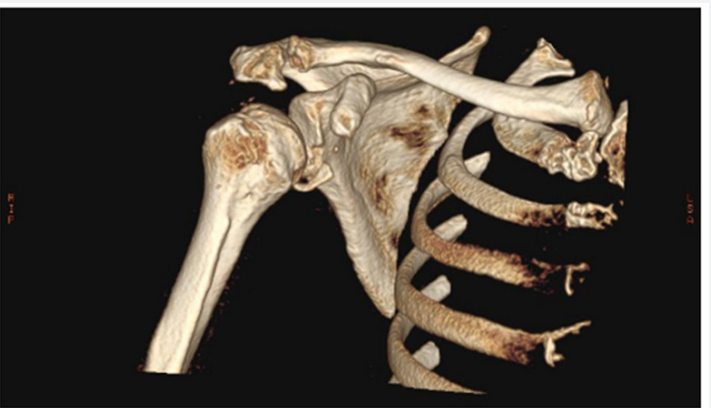

Figure 2: Reconstructed CT illustrating a post-reduction view of the Glenohumeral joint. The CT demonstrates bony Bankart and Hill Sachs Lesions associated with anterior shoulder dislocation.

A closed reduction of the shoulder was performed (Figure 2) and an examination under anaesthesia demonstrated a degree of instability over 100 degrees of abduction. The shoulder was immobilized in an arm sling and a wrist drop splint was applied. A computed tomography (CT) scan confirmed the presence of a glenoid rim fracture along with bony Bankart and Hills-Sachs lesions (Figure 3). An electromyography (EMG) was performed at 6 weeks, which demonstrated severe motor neuropathy, non-recordable latency and conduction velocities distally and proximally in the right radial motor nerve distribution (Tables $1 \mathrm{~A} \& 1 \mathrm{~B}$ ). The patient began a course of physiotherapy and rehabilitation 6 weeks postop. At latest follow up at three months, there was no evidence of recovery of the motor branch of the radial nerve clinically, however, it was noted that the superficial radial nerve sensation had returned to normal. After 1 year, there was no change in the outcome.

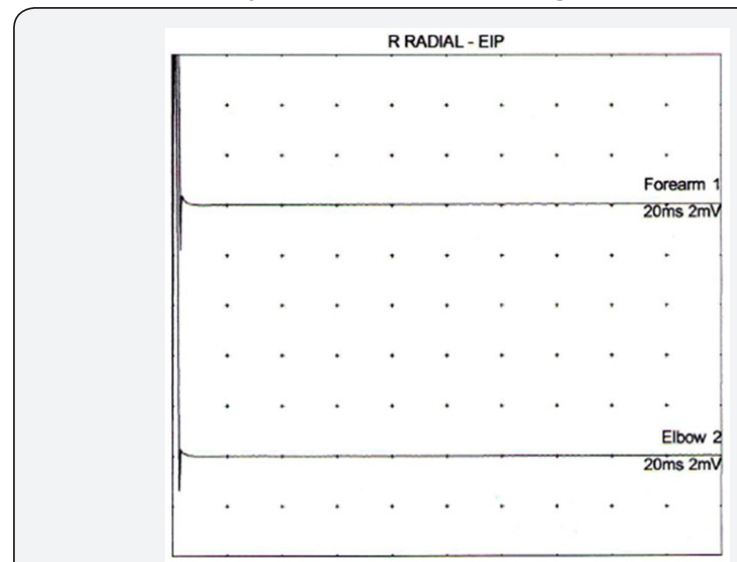

Figure 3: Electromyogram of the right Extensor Indicis Proprius Absent distal and proximal potentials in right radial motor nerve.

Table 1A: Sensory Nerve Conduction Study.

\begin{tabular}{|c|c|c|c|c|c|}
\hline $\begin{array}{c}\text { Nerve / } \\
\text { Sites }\end{array}$ & $\begin{array}{c}\text { Recording } \\
\text { Site }\end{array}$ & $\begin{array}{c}\text { Latency } \\
(\mathbf{m s})\end{array}$ & $\begin{array}{c}\text { Peak } \\
\text { Ampl } \\
(\mathbf{m V})\end{array}$ & $\begin{array}{c}\text { Distance } \\
(\mathbf{c m})\end{array}$ & $\begin{array}{c}\text { Velocity } \\
(\mathbf{m} / \mathbf{s})\end{array}$ \\
\hline \multicolumn{5}{|c|}{ R RADIAL - Thumb } \\
\hline Forearm & Thumb & 2.55 & 4.5 & 13 & 50.9 \\
\hline
\end{tabular}

Table 1B: Motor Nerve Conduction Study. .

\begin{tabular}{|c|c|c|c|c|}
\hline $\begin{array}{c}\text { Nerve / } \\
\text { Sites }\end{array}$ & $\begin{array}{c}\text { Latency } \\
\text { (ms) }\end{array}$ & $\begin{array}{c}\text { Ampl } \\
\text { (mV) }\end{array}$ & $\begin{array}{c}\text { Distance } \\
\text { (cm) }\end{array}$ & $\begin{array}{c}\text { Velocity } \\
\text { (m/s) }\end{array}$ \\
\hline \multicolumn{5}{|c|}{ R RADIAL - Extensor Indicis Proprius } \\
\hline Forearm & $\begin{array}{c}\text { No } \\
\text { Response }\end{array}$ & No Response & & \\
\hline Elbow & $\begin{array}{c}\text { No } \\
\text { Response }\end{array}$ & No Response & $\begin{array}{c}\text { No } \\
\text { Response }\end{array}$ \\
\hline
\end{tabular}

\section{Discussion}

The shoulder joint is the most frequently dislocated joint and it is attributed to the minimal inherent stability and few osseous restraints between the articulation of the proximal humerus and the glenoid cavity. Dislocation of the shoulder is considered to be a surgical emergency that requires urgent reduction to prevent compromise of the neurovascular structures and future instability of the joint [4]. Anterior shoulder dislocations have been reported in over $95 \%$ of cases [5]. The incidence of an anterior shoulder dislocation shows a bimodal age distribution where the majority of dislocations being sustained by young adults following high-energy injuries to the shoulder. The second age group is represented by older patients who have sustained low energy injuries [5].

Males are affected more than females especially in adolescents and young adults under 25 years. However, Visser et al. [2] demonstrated that most elderly patients were female, perhaps due to the long-life expectancy of women, and that the younger males are more prone to injury due to participation in sport [2]. Dislocation of the shoulder is associated with several complications, the rate of which could be as high as $26 \%$ [6]. Despite the variability in the reported incidence between different studies, the most common complication reported is nerve injury [1,7-9]. Several studies have reported the incidence of nerve injuries ranging from 19\% to 55\% [10-14]. In one series, out of 108 patients (60 years or older) with anterior shoulder dislocations, $9.3 \%$ had an injury of the axillary nerve, all of which resolved by 3-12 months [9].

Of note, there is a higher incidence of nerve damage in the elderly population [14]. The higher incidence of nerve injury in this age group may be attributed to age-related degenerative changes in the neural tissue [15]. Additionally, weakness in muscle tone and strength exacerbates the severity of displacement of the head of the humerus, thereby being more prone to nerve injury [9]. According to Visser et al. [2], the axillary nerve is the most commonly injured nerve following shoulder dislocation due to its close association with the glenohumeral joint and its course around the surgical neck of the humerus [2]. This study described a $42 \%$ incidence of damage to the axillary nerve followed by a $14 \%$ incidence in injury to the suprascapular nerve. Injury to the musculocutaneous nerve had an incidence of $12 \%$ [2]. Toolean et al. [13] reported similar findings with an incidence of $65.4 \%$ of axillary nerve injury in patients aged 40 years or older. Incidence of damage to the suprascapular nerve was seen in $3.6 \%$ of patients within the same age group [13]. 
The mechanism of associated nerve injury results from overstretching of nerves over the humeral head during its dislocation [1]. The traction on the brachial plexus is exerted laterally at a point distal from the anatomical anchorage to the spinal cord. Therefore, the elasticity of nerve roots prevents them from severe injury. The pattern of injury is largely the determining factor of nerve damage. Although dislocations caused by falls mainly result in axillary nerve injury, atypical lesions cannot be ruled out [1].

Isolated injuries to the radial nerve are less commonly reported in literature and can be missed due to its rare association with anterior shoulder dislocations, especially in the elderly since they are prone to immobilization and stiffness [14].

Radial nerve palsies are more commonly associated with humeral fractures especially those that occur at the junction of the middle and distal thirds of the humerus (Holstein-Lewis fracture). Humeral fractures are less commonly reported following anterior shoulder dislocations. This has several implications as long periods of stretch and compressive force can result in vascular compromise and neuronal ischemia and cause neurapraxia of the injured nerve [6]. Examination and documentation of nerve injuries in shoulder dislocations both before and after reduction must be reiterated to all clinicians involved in the management of these acute injuries as recommended by Yeap [1].

Although it is not necessary to carry out EMG routinely, it is essential to perform an EMG after 3 weeks to rule out paralysis and paresis. If there is no electrophysiological or clinical improvement after 2-3 months, surgical exploration is indicated. A delay in surgical exploration is associated with a poor outcome after nerve repair. In a study by Peron et al. [16] 75\% of patients with initial sensory deficits had improved following reduction [16]. Visser et al. [2] reported 33 of 37 patients who had EMG evidence of nerve injury showed complete recovery on EMG and regain of normal strength [1]. Physiotherapy plays an important role in maintaining the mobility until the normal motor function returns.

The surgical approach to management of nerve injury is based on several factors. The extent of damage to the nerve and the nerve's functional viability are the two prime factors. However, the location, extent of injury and the patient's medical condition should also be considered. In addition, it is important to assess whether the potential benefits to the patient outweighs the surgical risk, costs and loss of productivity following nerve repair surgery $[17,18]$.

It is important to note that although complete nerve lesions have a poorer outcome, the prognosis of nerve lesions after a dislocation of the shoulder joint is favourable. This was demonstrated in a study by Gumina et al. [9] which reported patients who had weakness at abduction of the shoulder, with a decreased threshold of sensation at the area of the deltoid. EMG studies proved axonotmesis in 3 of the 10 elderly patients with axillary nerve injury, whereas 7 experienced neurapraxia. However, all recovered within a period of 3-6 months.

\section{Conclusion}

Identification of any nerve injury, pre- and post-reduction is crucial to determine the appropriate patient management, thereby reducing the significant morbidity and improving overall prognosis. Medical professionals should be vigilant in their clinical examinations as isolated radial nerve palsy is a possible complication after traumatic shoulder dislocations. Nerve conduction studies are an important investigative tool that should be performed as part of the patient assessment particularly with associated nerve palsies.

It is vital to counsel such patients regarding the management plan and potential length of rehabilitation required for such injuries, a multidisciplinary approach should be adopted to ensure the best possible outcome is achieved.

\section{ACKNOWLEDGEMENTS}

Declared none

\section{CONFLICT OF INTERESTS}

The authors confirm that this article has no conflict of interest.

\section{References}

1. Yeap JS, Lee DJ, Fazir M, Kareem BA, Yeap JK (2004) Nerve injuries in anterior shoulder dislocations. Med J Malaysia 59(4): 450-454.

2. Visser CP, Coene LN, Brand R, Tavy DL (1999) The incidence of nerve injury in anterior dislocation of the shoulder and its influence on functional recovery. J Bone Joint Surg Br 81(4): 679-685.

3. Delbet P, Cauchoix A (1910) Les paralysies dans les luxations de l'epaule. Rev Chir 41: 327.

4. Hovelius L, Augustini BG, Fredin H, Johansson O, Norlin R, et al. (1996) Primary anterior dislocation of the shoulder in young patients. A tenyear prospective study. J Bone Joint Surg Am 78(11): 1677-1684.

5. Cutts S, Prempeh M, Drew S (2009) Anterior shoulder dislocation. Ann R Coll Surg Engl 91: 2-7.

6. Tuncel U, Turan A, Kostakoglu N (2011) Acute closed radial nerve injury. Asian J Neurosurg 6(2): 106-109.

7. Rowe CR (1956) Prognosis in dislocations of the shoulder. J Bone Joint Surg 38(5): 957-977.

8. Kroner K, Lind T, Jensen J (1989) The epidemiology of shoulder dislocations. Arch Orthop Trauma Surg 108(5): 288-290.

9. Gumina S, Postacchini F (1997) Anterior dislocation of the shoulder in elderly patients. J Bone Joint Surg 79(4): 540-543.

10. Blom S, Dahlback LO (1970) Nerve injuries in dislocations of the shoulder joint and fractures of the neck of the humerus. A clinical and electromyographical study. Acta Chir Scand. 136(6): 461-466.

11. Bumbasirevic M, Lesic A, Vidakovic A, Sudic V (1992) Nerve lesions after acute anterior dislocation of the humero-scapular joint--electro diagnostic study. Med Pregl 46(5-6): 191-193.

12. Ebel R (1973) Uber die ursachen der axillaris paresen beischulter luxationen. Monatsschr Unfallheilk D 76: 445-449.

13. Toolanen G, Hildingsson C, Hedlund T, Knibestol M, Oberg L (1993) Early complications after anterior dislocation of the shoulder in patients over 40 years: an ultrasonographic and electromyography study. Acta Orthop Scand 64(5): 549-552. 
14. De Laat EA, Visser CP, Coene LN, Pahlplatz PV, Tavy DL (1994) Nerve lesions in primary shoulder dislocations and humeral neck fractures. A prospective clinical and EMG study. Bone Joint J 76(3): 381-383.

15. Sunderland S (1972) Nerves and nerve injuries. Churchill Livingstone, Edinburgh, Scotland, p. 42.

16. Perron AD, Ingerski MS, Brady WJ, Erling BF, Ullman EA (2003) Acute complications associated with shoulder dislocation at an academic emergency department. J Emerg Med 24(2): 141-145.

17. Schwartz SI (1999) Principles of Surgery. ( $7^{\text {th }}$ edn), McGraw-Hill, New York, USA, pp. 2048-2053.

18. Perlmutter GS (1999) Axillary nerve injury. Clin Orthop Relat Res 368: 28-36.

\section{Your next submission with Juniper Publishers} will reach you the below assets

- Quality Editorial service

- Swift Peer Review

- Reprints availability

- E-prints Service

- Manuscript Podcast for convenient understanding

- Global attainment for your research

- Manuscript accessibility in different formats

( Pdf, E-pub, Full Text, Audio)

- Unceasing customer service

Track the below URL for one-step submission https://juniperpublishers.com/online-submission.php 